\title{
A Three-exponential Decay Empirical Model of TVOC Emission from Indoor Building materials
}

\author{
Yan Zhang ${ }^{1,2, *}$, Yongfa $\mathrm{Wu}^{1,2}$, Yuru $\mathrm{Niu}^{1,2}$, Yang Liu ${ }^{1,2}$, and Jinxia Jiang ${ }^{1,2}$ \\ ${ }^{1}$ School of Science, Beijing University of Civil Engineering and Architecture, Beijing 100044, China \\ ${ }^{2}$ Beijing Key Laboratory of Functional Materials for Building Structure and Environment Remediation, Beijing University of Civil \\ Engineering and Architecture, Beijing 100044, China
}

\begin{abstract}
The purpose of this article is to simulate the TVOC release of building materials in the environment chamber. Based on the theory of mass transfer, a three-exponential decay empirical model is proposed. The validity of the model is verified by experimental data and comparison with the classical model. From the fitting results, the new model is more consistent with the experimental data.
\end{abstract}

\section{Introduction}

Building materials can affect indoor air quality. Formaldehyde and Volatile Organic Compounds (VOCs) released from furnishings and decorative materials in buildings are closely related to the health and our lives [1-3]. The emission of VOCs from building materials is complex and can have a long-term release period. Hence, it is important to study the transport and emission behaviors of VOCs from building materials in detail.

Prediction models for indoor building materials such as the emission of formaldehyde and VOCs mainly include empirical model and physical mass transfer model[4-5]. Based on a large number of experimental data, the empirical model is established. By fitting the relationship between emission rate and emission time, a prediction model is established to predict long-term emission. Initially, based on the analysis of pollutant emission from typical building materials, a power-law model was proposed by the American Office Furniture Association [6]. However, the model assumes that the emission source is a non-decay source, which is quite different from the actual emission characteristics of building materials.

In addition, the exponential model is also one of the commonly used empirical models to predict the emission. Guo et al [7] developed the empirical models, such as the first-order decay model, the double-exponential decay model. The first-order decay model fits well the short-term emission of VOCs from building materials, but its prediction results for long-term emission are low[8]. Based on the assumption that building materials can release pollutants indefinitely, the double-exponential decay model can better predict the long-term emissions of VOCs, but the prediction results are high [9]. In fact, a large number of experimental data are needed to determine the empirical parameters, so the generality of the model is poor. Moreover, the empirical model lacks physical basis, and it is difficult to explain the mechanism of pollutant emission. Thus, physical models based on mass transfer mechanism are more popular to most researchers for modeling VOCs emission.

The mass transfer model takes into account the diffusion process of formaldehyde, VOCs and other pollutants in the interior of building materials, the interface between building materials and air, and the exterior of building materials to analyze the mass transfer characteristics of pollutants. Based on this theory, Little et al. [10] explored the transport of formaldehyde from medium-density fiberboard in an environmental chamber and proposed a single-phase mass transfer model. However, there is a deviation between the predicted value and the measured value. Zhang and $\mathrm{Xu}$ [11] established an analytical model with the convective mass transfer. Furthermore, based on the relationship between VOC emissions in building materials and the concentration of VOCs in air, Deng and Kim [12] further studied this model and the prediction accuracy had been improved. Much more researches associated with mass transfer model have been extensively presented in the literature [13-17]. The parameters of mass transfer model have practical physical significance. But these parameters usually depend on additional testing or model solving. Therefore, it is crucial to establish a simple and practical model for predicting the emission of building materials.

The purpose of this study is to establish a simple and practical analysis model to investigate the TVOC emission rate in environmental chamber. The model is based on the coupling of convection mass transfer and the mass balance equation in the environment chamber. By fitting the experimental data and comparing with the classical model, it can be seen that the model is in good agreement with the experimental data.

\section{Model development}

* Corresponding author: zhangyan1@bucea.edu.cn (Y. Zhang). 
Considering that the release of VOCs occurs not only in the interface between building materials and air, but also in the air. The two periods of VOCs emission should be discussed simultaneously.

At the material-air interface, the concentration of VOCs in the material phase is greater than that in the air phase because the material can adsorb VOCs [18]. There is a certain relationship between VOCs concentration in materials and environmental chamber, which can be written as [12]:

$$
\left.C\right|_{x=\delta}=K_{m a} C_{a i}
$$

where $C$ is the concentration in the material, $K_{m a}$ is the interface partition coefficient of VOCs between the material and the environmental chamber. $C_{a i}$ is the concentration in the interface, $\delta$ is the the thickness of the material.

The emission of VOCs is affected by the surface pore structures of building materials. Because VOCs are released through the surface pores of building materials, it is very important to take areal porosity into account. The convective mass transfer at the material-air interface is modified as follows [19-20]:

$$
-\left.\varepsilon D \frac{\partial C}{\partial x}\right|_{x=\delta}=h\left(\left.\frac{C}{K_{m a}}\right|_{x=\delta}-C_{a i r}\right)
$$

where $\varepsilon$ is the areal porosity, which is tested and calculated by mercury intrusion porosimetry, and $h$ is the convective mass transfer coefficient.

The mass balance equation in the environment chamber takes into account the process of VOCs diffusion from the surface of building materials to the environment chamber by convective mass transfer, that is, the change of pollutants in the environment chamber is equal to the release of pollutants on the surface of building materials minus the removal of pollutants at the vent [21]. Compared with the empirical model, it overcomes the disadvantage of not explaining the diffusion mechanism.

The mass balance in the environment chamber can be established under the following assumptions: (1) there is no VOCs in the air injected into the environment chamber; (2) assuming that VOCs are completely mixed in the ambient chamber. The expression is as follows:

$$
\frac{d C_{a i r}}{d t}=-\left.L \varepsilon D \frac{\partial C}{\partial x}\right|_{x=\delta}-N C_{\text {air }}
$$

The initial conditions are as follows:

$$
C_{\text {air }}(0)=0 \text {. }
$$

Assuming that the concentration of VOCs at the boundary is exponential decay, which can be written as [12]:

$$
\left.C\right|_{x=\delta}=A e^{-B t}+C_{\infty}
$$

where $C_{\infty}$ is the chemical reaction term.
By the combination of Eqs. (1)-(3), the Eq. (3) can be written as follow:

$$
\frac{d C_{a i r}}{d t}+(L h+N) C_{a i r}=\left.\operatorname{Lh} \frac{C}{K_{m a}}\right|_{x=\delta} .
$$

Substituting Eq. (5) into Eq. (6), the equation is established as:

$$
\begin{gathered}
\frac{d C_{a i r}}{d t}+(L h+N) C_{a i r}=\frac{L h}{K_{m a}}\left(A e^{-B t}+C_{\infty}\right) \\
C_{a i r}=e^{-\int(L h+N) t}\left[\int \frac{L h}{K_{m a}}\left(A e^{-B t}+C_{\infty}\right) \mathrm{e}^{\int(L h+N) d t} d t+C_{1}\right] \\
=C_{1} e^{-\int(L h+N) t}+\frac{L h C_{\infty}}{K_{m a}(L h+N)}+\frac{A L h}{K_{m a}} \frac{1}{L h+N-B} e^{-B t} \\
C_{a i r}(0)=C_{1}+\frac{L h C_{\infty}}{K_{m a}(L h+N)}+\frac{A L h}{K_{m a}(L h+N-B)}=0 \\
C_{1}=-\frac{L h C_{\infty}}{K_{m a}(L h+N)}-\frac{A L h}{K_{m a}(L h+N-B)}
\end{gathered}
$$

So, the environmental chamber $C_{a i r}$ can be expressed as:

$$
\begin{gathered}
C_{a i r}=-\left(\frac{L h C_{\infty}}{K_{m a}(L h+N)}+\frac{A L h}{K_{m a}(L h+N-B)}\right) e^{-(L h+N) t} \\
+\frac{A L h}{K_{m a}(L h+N-B)} e^{-B t}+\frac{L h C_{\infty}}{K_{m a}(L h+N)}
\end{gathered}
$$

The final form is as follow:

$$
C_{\text {air }}=a e^{-b_{1} t}-\left(a+c_{1}\right) e^{-b_{2} t}+c_{1}
$$

If the chemical reaction is not existed and the exponential decay adsorption of the environmental chamber is taken into account, Eq. (13) can be extended to the following three-exponential decay empirical model

$$
C_{a i r}=a e^{-b_{1} t}-a e^{-b_{2} t}-c e^{-b_{3} t}
$$

\section{Results and discussion}

Based on the environmental chamber experiment, this paper tested the TVOC emission of different materials, such as waterproof paint and floor coating, and the results are obtained through experimental fitting.

Fig. 1 shows the release of waterproof paint. In the early stage, there is a process of filling the chamber, i.e. the chamber concentration reaches its maximum rapidly. And the concentration declined slowly in the later stage of release. Comparing the present model with the classical model, it can be seen that the deviation between the classical model and the experimental data is greater, while the present model fits better in both early and late 
stages of release. Simultaneously, the fitting parameters and root mean square error (rmse) are shown in Table 1, which further verifies the above viewpoint.

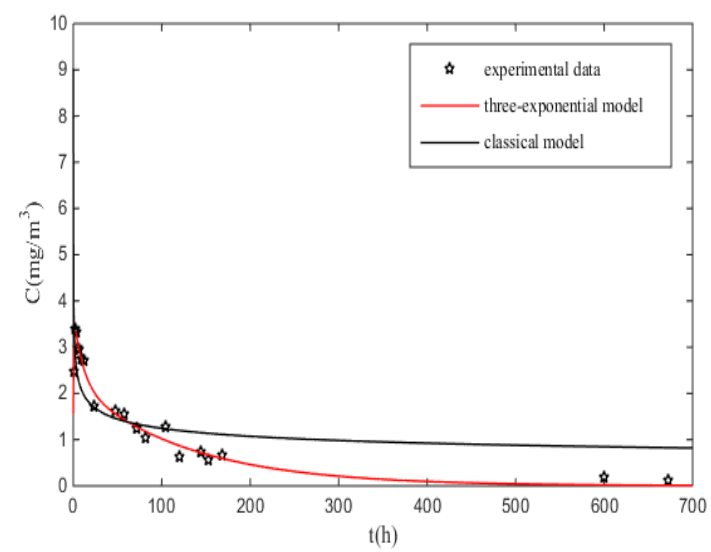

Fig. 1. Chamber concentration of TVOC emitted from waterproof paint.

Table 1. Fitting parameters of figure 1

\begin{tabular}{ccccccc}
\hline Model & $\boldsymbol{a}$ & $\boldsymbol{b}_{\mathbf{1}}$ & $\boldsymbol{b}_{\mathbf{2}}$ & $\boldsymbol{b}_{\mathbf{3}}$ & $\boldsymbol{c}$ & rmse \\
\hline $\begin{array}{c}\text { Present } \\
\text { model }\end{array}$ & 2.242 & $\begin{array}{c}- \\
1.547\end{array}$ & 0.008 & 1.373 & 0.095 & 0.144 \\
$\begin{array}{c}\text { Classical } \\
\text { model }\end{array}$ & 3.351 & 0.215 & - & - & - & 0.586 \\
\hline
\end{tabular}

The TVOC release of floor coating is shown in Fig. 2. It can be seen that the release law of floor material is consistent with that of waterproof paint. The concentration in chamber rises at first and then decreases slowly. Furthermore, the numerical simulation shows that the present model is superior to the classical model in the whole release process. The corresponding values of parameters and root mean square error (rmse) are given in Table 2, which further verified the validity of the three-exponential model.

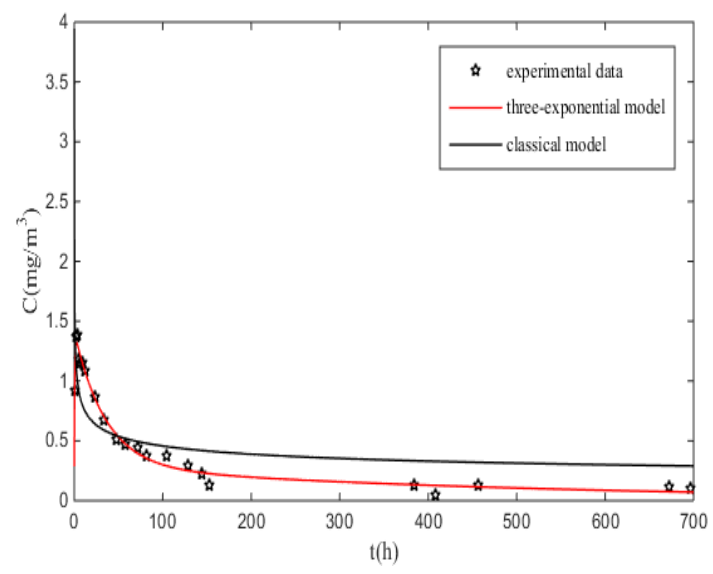

Fig.2. Chamber concentration of TVOC emitted from floor coating.

Table 2. Fitting parameters of figure 2

\begin{tabular}{|c|c|c|c|c|c|c|}
\hline Model & $a$ & $b_{1}$ & $b_{2}$ & $b_{3}$ & $c$ & rmse \\
\hline $\begin{array}{c}\text { Present } \\
\text { model }\end{array}$ & 1.129 & $\begin{array}{c}- \\
0.287\end{array}$ & 0.029 & 1.871 & 0.002 & 0.049 \\
\hline $\begin{array}{c}\text { Classical } \\
\text { model }\end{array}$ & 1.343 & 0.234 & - & - & - & 0.255 \\
\hline
\end{tabular}

\section{Conclusions}

A new three-exponential decay empirical model is proposed to describe TVOCs emission. The validity of this model can be verified by comparing classical model. The results show that the model can describe the release characteristics of TVOC more accurately, and it is highly consistent with the experimental data.

\section{Acknowledgment}

This work is supported by the National Key Research Program of China (No. 2016YFC0700601), the National Natural Science Foundation of China (No. 21878018), the Joint Funding Project of Beijing Municipal Natural Science Foundation and Beijing Municipal Education Commission (No. KZ201810016018).

\section{References}

1. L. Mølhave, G. Clausen, B. Berglund, J. De Ceaurriz, A. Kettrup, T. Lindvall, M. Maroni, A.C. Pickering, U. Risse, H. Rothweiler, B. Seifert, M. Younes, Total volatile organic compounds (TVOC) in indoor air quality investigations, Indoor Air 7 (1997) 225-240.

2. M. Reitzig, S. Mohr, B. Heinzow, H. Knöppel, VOC emissions after building renovations: traditional and less common indoor air contaminants, potential sources, and reported health complaints, Indoor Air 8 (1998) 91-102.

3. L. Elliott, M.P. Longnecker, G.E. Kissling, S.J. London, Volatile organic compounds and pulmonary function in the third national health and nutrition examination survey, 1988-1994, Environ. Health Perspect. 114 (2006) 1210-1214.

4. Z. Liu, W. Ye, J.C. Little, Predicting emissions of volatile and semivolatile organic compounds from building materials: a review, Build. Environ. 64 (2013) 7-25.

5. Y. Zhang, J. Xiong, J. Mo, M. Gong, J. Cao, Understanding and controlling airborne organic compounds in the indoor environment: mass transfer analysis and applications, Indoor Air, 26, 1 ( 2016) 39-60.

6. BIFMA M7.1-2011 A B. Standard Test Method For Determining VOC Emissions From Office Furniture Systems, Components And Seating. USA: American National Standards Institute, 2011.

7. Z. Guo, 2002. Review of indoor emission source models. Part 1. overview. Environ. Pollut. 120, 533e 549

8. X. Liu, M.A. Mason, Z. Guo, K.A. Krebs, N.F. Roache, Source emission and model evaluation of formaldehyde from composite and solid wood furniture in a full-scale chamber, Atmos. Environ. 122 (2015) 561-568.

9. H.S. Park, C. Ji, T. Hong, Methodology for assessing human health impacts due to pollutants 
emitted from building materials, Build. Environ. 95 (2016) 133-144.

10. J.C. Little, A.T. Hodgson, A.J. Gadgil, Modeling emissions of volatile organic compounds from new carpets, Atmos. Environ. 28, 2 (1994) 227-234.

11. Y.P. Zhang, Y. Xu, Characteristics and correlations of VOC emissions from building materials, Int. J. Heat Mass Transfer, 46, 25 (2003) 4877-4883.

12. B.Q. Deng, C.N. Kim, An analytical model for VOCs emission from dry building materials, Atmos. Environ. 38, 8 (2004) 1173-1180.

13. Y. Xu, Y.P. Zhang, A general model for analyzing single surface VOC emission characteristics from building materials and its application, Atmos. Environ. 38, 1 (2004) 113-119.

14. X.K. Wang, Y.P. Zhang, R.Y. Zhao, Study on characteristics of double surface VOC emissions from dry flat-plate building materials, Chinese Science Bulletin, 51, 18 (2006) 2287-2293.

15. T. Yang, P.P. Zhang, B.P. Xu, J.Y. Xiong, Predicting VOC emissions from materials in vehicle cabins: Determination of the key parameters and the influence of environmental factors, Int. J. Heat Mass Transfer, 110 (2017) 671-679.

16. X. Yang, Q. Chen, J.S. Zhang, R. Magee, J. Zeng, C.Y. Shaw, Numerical simulation of VOC emissions from dry materials, Build. Environ. 36, 10 (2001) 1099-1107.

17. Y. Xu, Y.P. Zhang, An improved mass transfer based model for analyzing VOC emissions from building materials, Atmos. Environ. 37, 18 (2003) 2497-2505.

18. J.W. Axley, Adsorption Modelling for Building Contaminant Dispersal Analysis, Indoor Air 1, 2 (1991) 147-171.

19. P. Mocho, V. Desauziers, H. Plaisance, N. Sauvat, Improvement of the performance of a simple box model using CFD modeling to predict indoor air formaldehyde concentration, Build. Environ. 124 (2017) 450-459.

20. Y. Zhang, J.X. Jiang, Y. Bai, J.M. Liu, H.Q. Shao, C.D. Wu, Z.B. Guo, A fractional mass transfer model for simulating VOC emissions from porous, dry building material, Build. Environ. 152 (2019) 182-191.

21. W.W. Liu, Y.P. Zhang, Y. Yao, Labeling of volatile organic compounds emissions from Chinese furniture: consideration and practice, Chinese Science Bulletin, 58, 28/29 (2013) 3499-3506. 